\title{
Study of Benign Adnexal Tumors of The Skin: An Institutional Five Year Study of 106 Cases
}

\author{
${ }^{1}$ Manibarathi R, ${ }^{* 2}$ Dhanalakshmi S, ${ }^{3}$ Suganthi C, ${ }^{4}$ Shobana B \\ Institute Of Pathology, Madras Medical College, Chennai \\ Corresponding author: $*$ Dhanalakshmi $S$
}

\begin{abstract}
Background: Benign adnexal tumor of skin is not commonly encountered in routine practice of surgical pathology. They exhibit heterogenous histological patterns. In both diagnostic and therapeutic point of view, it is essential to recognize these tumors.

Objectives: This study was undertaken with the aim of assessing the incidence, clinicopathological characteristics and histopathological features of each cutaneous adnexal tumor.

Material and methods: A retrospective study was conducted for 5 years period from year 2011 to 2015 in the Institute of pathology, Madras Medical College, Chennai. Histopathological features were evaluated and their correlations with clinicopathological features were studied.

Results: In this present study, when compared to the total burden of all cases reported in our institute, cutaneous adnexal neoplasm accounts for only 0.3\%. There is slight female predilection. Among the 106 cases 58 cases show sweat gland differentiation followed by follicular differentiation ( 46 cases) and 2 cases showed sebaceous gland differentiation.
\end{abstract}

Conclusion: Incidence of Cutaneous benign adnexal neoplasms is relatively low with majority of tumors show differentiation along the sweat glands, commonly located in head and neck region in the $3^{\text {rd }}$ to $4^{\text {th }}$ decade.

Keywords: Benign adnexal tumors, Hair follicle, sweat gland, sebaceous gland.

\section{Introduction}

Benign adnexal tumor of skin are uncommon comprises extensive array of tumors, that demonstrate differentiation towards any one of the cutaneous appendages like hair follicle, eccrine, apocrine gland and sebaceous gland $[1,2,3]$. Since all cutaneous adnexae originate from pluripotent stem cells, one neoplasm can exhibit differentiation along two or more adnexal lines that leads to difficulties in making the precise diagnosis $[1,3,4,5]$. Although the precise categorization does not make a difference in the clinical management, some of them might be indicators of syndromes associated with proneness to internal malignancy such as trichelemmomas in Cowdens disease and sebaceous tumors in Muin-Torre syndrome[6].

\section{Materials And Methods}

This present study is a retrospective study conducted for a period of 5 years from 2011 to 2015. Clinical data such as age, gender, site of the lesion and clinical diagnosis were obtained from histopathological records. Formalin fixed Parrafin embedded hematoxylin and eosin stained sections were examined in light microscopy. Histopathologically proven benign adnexal tumors were included in this study. Other skin tumors were excluded from this study.

\section{Observation And Results}

A total of 106 cases were diagnosed during this period of 5 years in our department.

Table 1: Gender distribution of benign adnexal tumors.

\begin{tabular}{|l|l|l|l|}
\hline S. NO & Gender & Number of cases & Percentage of cases \\
\hline 1 & Male & 52 & $49.05 \%$ \\
\hline 2 & Female & 54 & $\mathbf{5 0 . 9 5 \%}$ \\
\hline
\end{tabular}

We found that there was a slight female preponderance $(50.95 \%)$ in our study.

Table 2: Site distribution of tumors

\begin{tabular}{|l|l|l|l|}
\hline S. NO & Site & Number of cases & Percentage of cases \\
\hline \multirow{3}{*}{1} & Head and neck & 67 & $\mathbf{6 3 . 2 \%}$ \\
\cline { 2 - 4 } & Scalp & 42 & $39.6 \%$ \\
& Face & 22 & $20.7 \%$ \\
& Neck & 3 & $2.83 \%$ \\
\hline 2 & Upper extremity & 19 & $17.9 \%$ \\
\hline 3 & Lower extremity & 10 & $9.43 \%$ \\
\hline 4 & Trunk & 10 & $9.43 \%$ \\
\hline
\end{tabular}


We observed that most common site was head and neck (63.2\%) followed by upper extremity (17.9\%).

Table 3: Age distribution of tumors

\begin{tabular}{|l|l|l|l|}
\hline S.NO & Age range(years) & Number of cases & Percentage of cases \\
\hline 1 & $<20$ & 14 & $13.2 \%$ \\
\hline 2 & $21-30$ & 16 & $15.09 \%$ \\
\hline 3 & $31-40$ & 27 & $\mathbf{2 5 . 4 7 \%}$ \\
\hline 4 & $41-50$ & 22 & $20.75 \%$ \\
\hline 5 & $51-60$ & 19 & $17.92 \%$ \\
\hline 6 & $61-70$ & 5 & $4.71 \%$ \\
\hline 7 & $71-80$ & 3 & $2.83 \%$ \\
\hline
\end{tabular}

We found that most common age group affected was 31-40 years (25.47\%) followed by 41-50 years $(20.75 \%)$.

Table 4: Distribution according to line of differentiation

\begin{tabular}{|l|l|l|l|}
\hline S.NO & Line of differentiation & Number of cases & Percentage of cases \\
\hline 1 & Sweat gland tumors & 58 & $54.71 \%$ \\
\cline { 2 - 4 } & Nodular hidradenoma & 26 & $\mathbf{2 4 . 5 \%}$ \\
& Eccrine poroma & 5 & $4.71 \%$ \\
& Eccrine spiradenoma & 2 & $1.88 \%$ \\
& Eccrine acrospiroma & 5 & $4.71 \%$ \\
& Eccrine hidrocystoma & 1 & $0.94 \%$ \\
& Cylindroma & 1 & $0.94 \%$ \\
& Chondroid syringoma & 8 & $7.54 \%$ \\
& Syringocystadenoma papilliferum & 6 & $5.66 \%$ \\
& Apocrine hidrocystoma & 4 & $3.77 \%$ \\
\hline 2 & Hair follicle tumors & 46 & $11.33 \%$ \\
\cline { 2 - 4 } & Pilomatricoma & 27 & $\mathbf{2 5 . 4 \%}$ \\
& Proliferating trichelemmal tumor & 10 & $9.43 \%$ \\
& Trichoadenoma & 2 & $1.88 \%$ \\
& Trichoblastoma & 1 & $0.94 \%$ \\
& Trichoepithelioma & 6 & $5.66 \%$ \\
\hline 3 & Sebaceous gland tumors & $2 \%$ & $1.88 \%$ \\
\hline
\end{tabular}

We found that most common line of differentiation exhibited by tumors was sweat gland tumors $(54.71 \%)$ followed by hair follicle tumors $(11.33 \%)$.

\section{Discussion}

Cutaneous adnexal tumors exhibiting variety of overlapping clinical and histological features, makes the sub categorization more difficult [1]. Clinically it is impossible to distinguish these neoplasms from each other. This can be accomplished only by means of light microscopy by their histological patterns and their line of differentiation. We evaluated 106 cases in this study. A result of this study is in accordance with other previous studies $[3,7,8,9]$. The incidence of cutaneous adnexal tumor in present study was $0.3 \%$. Most cases were occurs in middle age group (31-40 years). Sweat gland tumour was the predominant adnexal neoplasm observed in this study with head and neck being the most common site. Pilomatricoma (calcifying epithelioma of Malherbe): (Figure 1) is the most common tumor encountered in our study. Histopathogically characterized by well circumscribed neoplasm composed of basaloid cells, shadow cells and areas of calcification. It needs to be differentiated from calcified trichelemmal cyst which lacks shadow or ghost cells, and is characterized by a cyst lined by cells with abundant eosinophilic cytoplasm in contrast to basaloid cells in pilomatricoma [10].

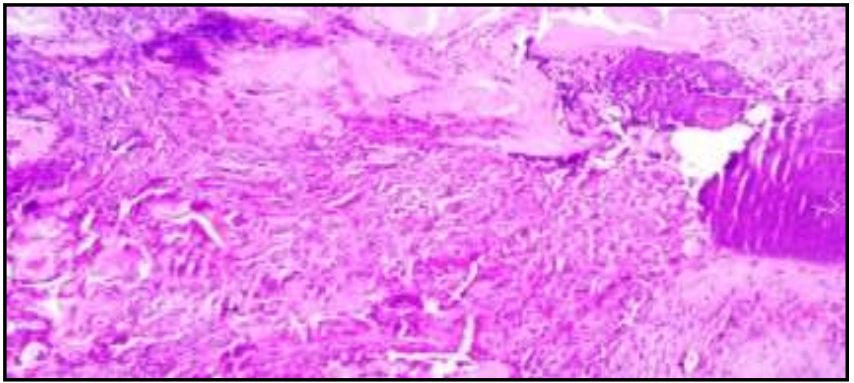

Figure 1: H\&E stain, $10 \mathrm{x}$ view: Pilomatricoma: shows basoloid cells and ghost cells

Nodular hidradenoma (Figure 2) is second commonly encountered tumor in our study. It is characterized by well circumscribed dermally located nodule composed of clear cells of polyhedral and fusiform cells with lumina lined by cuboidal cells with decapitation secretion often with cystic spaces [10]. It may be confused with trichelemmoma that exhibits clear cells, but lacks cystic spaces and tubular lumina. 


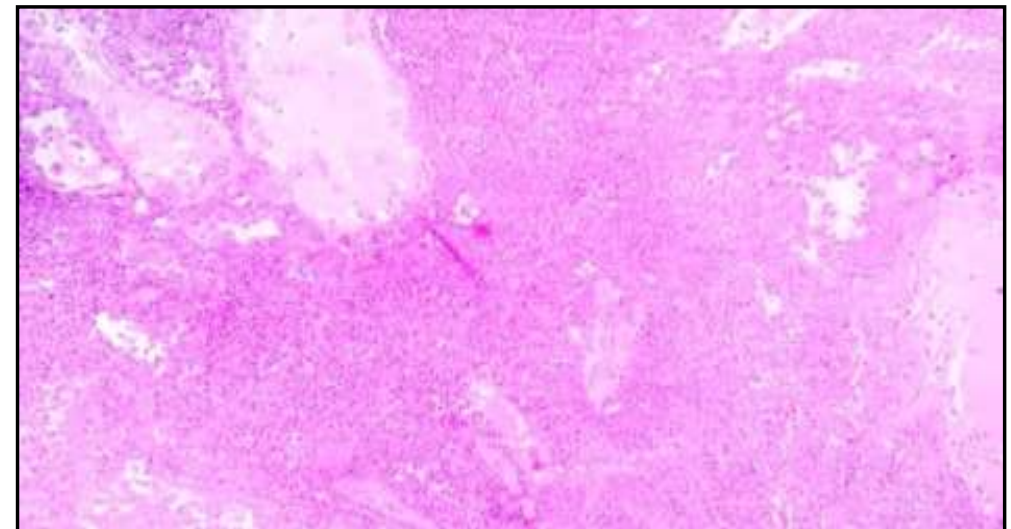

Figure 2: H\&E stain, $10 \mathrm{x}$ view: Nodular hidradenoma: shows nests and lobules of basaloid cells with cystic spaces.

Proliferating trichelemmal tumor (Figure 3): well demarcated lesion composed of irregularly shaped lobules of squamous epithelium exhibiting pallisading of peripheral cell layer with abrupt keratinization in the center of the lobules. This may raise diagnostic confusion with squamous cell carcinoma [10]. But absence of atypia, invasion and presence of well circumscription and amorphous keratin helps to make the diagnosis.

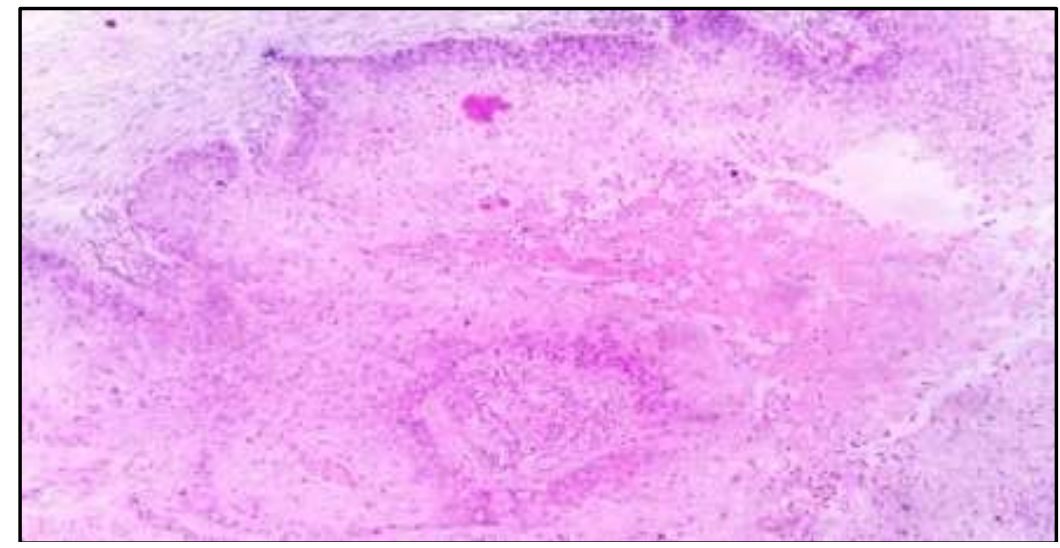

Figure 3: $\mathrm{H} \& \mathrm{E}$ stain, $10 \mathrm{x}$ views: Proliferating trichelemmal tumor: shows lobules of squamous epithelium with abrupt keratinisation.

Eccrine poroma (Figure 4) characterized by broad anastamosing bands of cuboidal cells emanating from epidermis and tubules lined by cuticular cells.

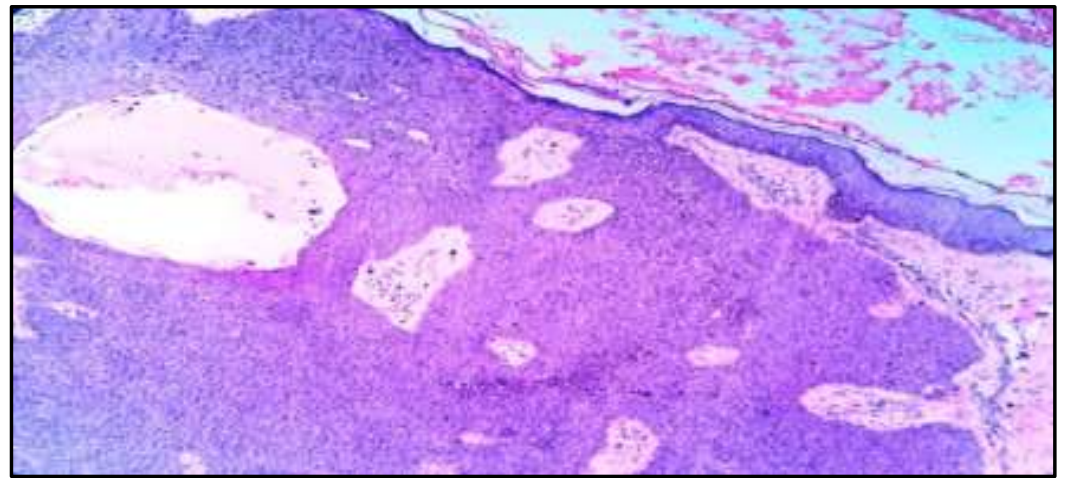

Figure4: H\&E stain, $10 \mathrm{x}$ views: Eccrine poroma: shows anastomosing bands of uniform basaloid cells with scattered ducts and cysts.

Other than these common tumors we also encountered sweat gland tumors such as eccrine hidrocystoma( Figure 5), Cylindroma,Chondroid syringoma, Syringocystadenoma papilliferum, Apocrine hidrocystoma and tumours showing trichelemmal differentiation such as Trichoadenoma, Trichoblastoma, Trichoepithelioma and tumours showing sebaceous gland differentiation such as sebaceous adenoma and sebaceoma.

$\begin{array}{llr}\text { DOI: } 10.9790 / 0853-1606085760 & \text { www.iosrjournals.org } & 59 \mid \text { Page }\end{array}$




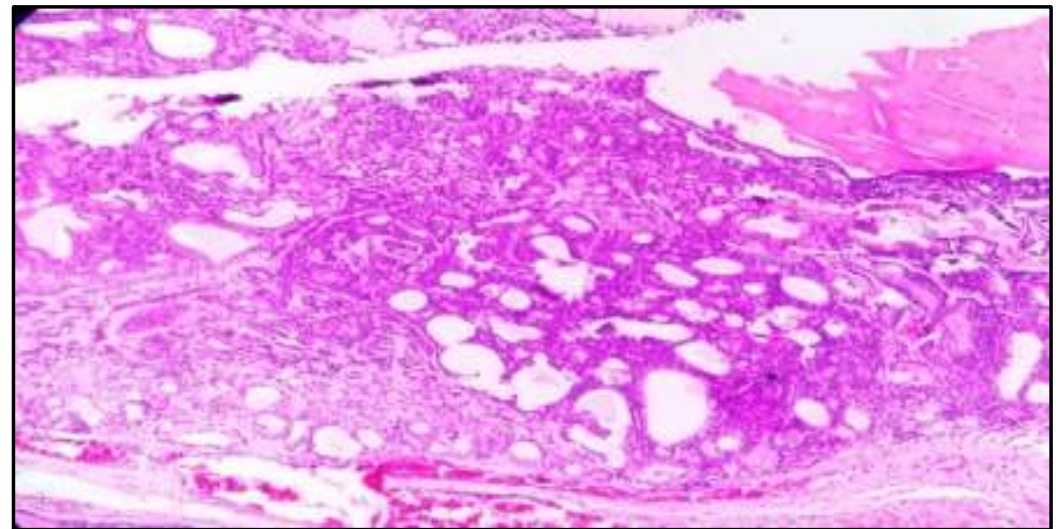

Figure 5: H\&E stain, $10 \mathrm{x}$ views: Eccrine hidrocystoma: shows small ductal cysts lined by cuboidal cells.

\section{Conclusion}

Making a precise diagnosis of cutaneous benign adnexal tumors is a challenging one, because they comprises extensive lists of entities and a spectrum of differentiation in a single tumor. To make accurate sub typing, a basic knowledge and understanding of embryology and histology of skin adnexal structures are essential.

\section{Conflict of interest:}

Nil

\section{Acknowledgement}

Nil

\section{References}

[1]. Vani D, Ashwini N.S, sandhya M, T.R.Dayanandha. Bharathi .M, A 5 Years Histopathological study Of Skin Adnexalttumours at a Tiertary Care Hospital. Journal of Dental and Medical Sciences. DOI: 10.99790/0853-14470105.

[2]. K O alsaad, N AObaidat, D Ghazarain, Skin adnexal neoplasm- part 1: An approach to tumours of pilosebaceous unit, J zclinzpathol 2007; 60: 12:44

[3]. U.Jindal, R.Patel: Study Of Adnexal Tumours Of The Skin A Three Year Study of 25 cases. The Internet Journal Of Pathology. 2012 Volume 13 Number 3. DOI: 10.5580/2bf5.

[4]. Moore To, Orman HL, Orman SK, etal. Poromas of Head and Neck. J Am Acad Dermatol. 2001;44:48-52.

[5]. $\quad \mathrm{R}$ jalakshmi Tirumalae and MO Roopa, Benign vs. malignant skin Adnexal Neoplasms: How Useful are Silhouttes?Indian J Dermatol.2013 Jan-Feb; 58(1):30-33. DOI: 10.4103/0019-5154.105282

[6]. Ramirez Claudia C, Berman Brian. Cutaneous Signs and Syndromes Associated with Internal Malignancies. SkinMed. 2005: 4(2): 84-90.

[7]. Patrick WB, Porcia TB, Bradford, Susan SD,Jorge RT. Cutaneous Appendageal Carcinoma Incidence and Survival Patterns in the United States: A Population Based Study Arch Dermatol. 2010;146(6):625-632.

[8]. Jayalakshmi P,Loomi LM, Cutaneous adnexal neoplasms in biopsy specimens processed in the department of Pathology, University of Malaya. ANN Acad Med Singapore. 1996 Jul;25(4):522-5.

[9]. Chayanika Pantola, Sanjay Kala, Asha Agarwal, Sonal Amit and Saurabh Pantola. Cutaneous adnexal tumours: A Clinicopathological descriptive study of 70 cases. World Journal of Pathology. 2013 Volume No 6.

[10]. David E. Elder Lever's Histopathology of Skin $10^{\text {th }}$ edition ( Lippincott Williams \& Wilkins, Wolters Kluwer.2008) 